\title{
Erratum to: Acute Cardiovascular Toxicity of Sterilizers, PHMG, and PGH: Severe Inflammation in Human Cells and Heart Failure in Zebrafish
}

Jae-Yong Kim • Hak Hyeon Kim • Kyung-Hyun Cho

Published online: 29 December 2012

(C) Springer Science+Business Media New York 2012

Erratum to: Cardiovasc Toxicol

DOI 10.1007/s12012-012-9193-8

The two first authors, Jae-Yong Kim and Hak Hyeon Kim, are co-first authors.

The online version of the original article can be found under doi:10.1007/s12012-012-9193-8.

J.-Y. Kim · H. H. Kim · K.-H. Cho ( $₫)$

School of Biotechnology, Yeungnam University, Gyeongsan

712-749, Republic of Korea

e-mail: chok@yu.ac.kr

J.-Y. Kim · H. H. Kim - K.-H. Cho

Research Institute of Protein Sensor, Yeungnam University,

Gyeongsan 712-749, Republic of Korea 